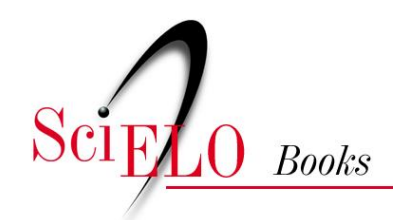

\title{
Seduepb
}

\section{Problematização quanto a qualidade e a cientificidade}

\author{
Pedro Bergamo
}

\section{SciELO Books / SciELO Livros / SciELO Libros}

BERGAMO, P. Educação universitária: práxis coletiva em busca de veraz qualidade e de precisa cientificidade [online]. Campina Grande: EDUEPB, 2012. Problematização quanto a qualidade e a cientificidade. pp. 73-107. ISBN 978-85-7879-189-6. Available from SciELO Books <http://books.scielo.org>.

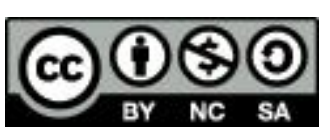

All the contents of this work, except where otherwise noted, is licensed under a Creative Commons Attribution-Non Commercial-ShareAlike 3.0 Unported.

Todo o conteúdo deste trabalho, exceto quando houver ressalva, é publicado sob a licença Creative Commons Atribuição Uso Não Comercial - Partilha nos Mesmos Termos 3.0 Não adaptada.

Todo el contenido de esta obra, excepto donde se indique lo contrario, está bajo licencia de la licencia Creative Commons Reconocimento-NoComercial-CompartirIgual 3.0 Unported. 


\section{Problematização quanto a qualidade e a cientificidade}

Inexiste determinação explícita do que deva ser entendido por qualidade do processo educativo, a par de que cientificidade deste mesmo processo não está intersubjetivamente a ser admitida como questão também qualificadora. A aceitação de que ciências, ética e arte-estética compõem a totalidade educativa ainda não se tornou condição em cuja prevalência se considere qualificativo inteirar o que há de compor a própria educação. Contrariamente, ciências estariam a caminho de ser excludente objeto desse processo. Neste aspecto, um mensurado nível mais alto de desempenho na aprendizagem estritamente de ciências passaria a ser aceitável como educação de qualidade. Assim, recorrência de "a" qualidade no discurso institucional-avaliativo das instituições educacionais traduz uma necessidade cuja persistente imprecisão transforma qualidade e cientificidade do processo educativo em um problema de inconsistência de concepções.

Já a obrigatoriedade de avaliação institucional, interna e externamente processada, tem por fulcro "padrões mínimos de qualidade de ensino, definidos como a variedade e quantidade mínimas, por aluno, de insumos indispensáveis ao desenvolvimento do processo de ensino-aprendizagem" (Lei 9.394 de 20.12.1996, Art. 4 , IX. Grifos nossos). Assim, ao se considerar que nos dicionários filosóficos não consta padrão como categoria, recorre-se a determinado léxico (BUENO, 
1988), nos quais o termo significa modelo oficial de peso e de medida. Paralelamente, insumos evocam teoria geral de sistemas. Então, na ausência de um sistema rigorosamente determinado como científico, restam poucas dúvidas de que o texto legal desvela tentativa de não adentrar o labirinto das inconsistências em que se situa a questão de "a" qualidade. Já esta questão há de continuar exposta a desvarios de ficção propagandista, em duas principais vertentes: (a) alegações de interesse institucional-público; e, (b) tácitas interessenças no âmbito da competição entre organizações privadas.

Se a lei se omite, as autoridades educacionais passam a legislar, à margem das atribuições próprias, sem avançar, senão retroceder, em tal questão. Disto tem sido inegável sintoma a determinação de mensurar qualidade, mediante expedientes de vezo sistêmico, recorrendo-se a exames de assimilação de acumuladas narrativas de saberes tidas por conhecimentos nos níveis de alunos ingressantes e de concluintes do processo de ensino-aprendizagem. Entretanto, desde Aristóteles (apud ABBAGNANO: 2007, p. 957-8), qualidade coincide com "qualquer determinação de um objeto" em resposta à pergunta "qual?", ultrapassando as propriedades ou características quantificáveis de tal objeto, as quais, na atualidade da concepção, perfazem condição secundária das determinações, enquanto a condição primária permanece fora do espaço perceptivo, em "um $x$ vazio" que, para Husserl (Ibid.) "se torna portador das determinações matemáticas e das fórmulas inerentes".

Em síntese, os educandos resultam nas principais vítimas da imprecisão sobre o que seja qualidade educacional e sobre a relação desta qualidade com eventual alcance científico do processo de ensino-aprendizagem. Não há ética e, inclusive, honestidade nos discursos a respeito. Mas, cabe engendrar ao 
menos hipótese de que tais discursos sejam deseducativos e que ultrapassá-los resultaria educativo.

Todavia, até a mera fundamentação dessa hipótese se vê ameaçada de incidir em iniciativa que se expõe a riscos de ser inconsequente, por enredar-se no paradoxo de estar coagida a atender ficção ilusionista e, ao mesmo tempo, buscar veracidade real. É o que, nesta unidade do texto, cabe peculiarmente problematizar.

Qualidade e cientificidade de educação universitária não têm emergido desalheadas em relação ao viés metropolístico de mero ensino superior. A inferência deste viés não está pronta, convindo investigá-lo em fontes caracterizadas por abertura crítica ${ }^{1}$.

Trata-se, a rigor, de recorrente e predizível silêncio quanto a se aperceber de que metropolismo coincide com sincrônico-topocentria, ou seja, com a cultural-artificialmente criada matriz de contraditórios - a tríade compreendida por hegemonismo político, abstracionismo epistemológico e reducionismo econômico.

$\mathrm{Na}$ estrutura dessa tríade, cujos tentáculos sustentatórios de tributação, de contribuições e de retornos (líquidos de tributação e de contribuições) açambarcam todas as fontes de meios de vida, não há como isentar as IES, inclusive as latino-americanas, de perfazerem o suporte gnoseológico de tal açambarcamento.

1 Dentre tais fontes, cabe destacar: CUNHA: 1978; 1983; 1983; 1988; 1989; 1999. DIAS SOBRINHO: 1999. CHAUÍ: 1999a; 1999b. RIBEIRO: 1969; NUNES: 1999b. Paralelamente, crítica e/ou defesa do viés metropolístico de todo o processo educativo caberia constar de fontes que abordem a influência liberal e neo-liberalista nesse processo, a exemplo de SILVA, 2002. LOMBARDI (Org.), 2003. LOMBARDI; SAVIANI; SANFELICE (Orgs.), 2005. SOUZA, 2005. 
Assim, viés metropolístico traduz o que, segundo Novaski (2005, p. 79-85), compõe algo de oculto no fenômeno do ensino superior, peculiarmente da pós-graduação "stricto sensu", além de incidir em funcionalidade sociológica ao "espírito do capitalismo" que, na Civilização Ocidental a se tornar global, move o "desenvolvimento universal em seu valor e significado” (WEBER: 1983, p. 1. Grifo no original).

\section{A. Concomitância de imprecisão sobre qualidade e de ameaça vinculada à obrigatoriedade de avaliação externa}

(Auto)-avaliação institucional é concepção que deriva de uma política educacional (declarada) pública no âmbito do macrossistema MEC-Inep. As implicações dessa política estão a merecer pesquisa e reflexão, peculiarmente da parte de responsáveis por faculdades particulares, isoladas e interiorizadas, a exemplo da IES em apreço - a Faculdade São Francisco de Barreiras/BA (FASB).

De antemão, e neste exemplo pelo menos, cumpre elucidar que (auto)-avaliação institucional se tornou inescapavelmente compulsória e, por isto, traduz-se em tensão dialética entre ameaça externa e oportunidade interna, a primeira de feitio burocrático-estratégico e a segunda administrativo-organizacional. Assim, caracterizar os teores dessa tensão, assim como as forças que os impulsionam, a par de certas implicações de sua (re)-produção, vem a ser o objetivo fundamental deste tópico a investigar.

Torna-se oportunidade interna no sentido de que há como induzir mudança, continuidade ou correção de rumos das atividades acadêmicas (ensino, pesquisa e extensão), 
precipitando estreitamento de interações nos três principais níveis institucionais: mantenedores (e seus funcionários), docentes e discentes.

Já a ameaça externa carece de atenção pouco ou nada encontradiça no pertinente marco regulamentar, bem como nas práticas avaliativas (à base de planejamento estratégico, acompanhamento e controle). Trata-se de ameaça que advém da condição de tais práticas compreenderem conteúdos imprecisos, fragmentados, extensos e pouco ou nada autopoliciados contra eventual mediação de tendências meramente ideológicas, além de estarem em franca dissonância com o alcance englobalizante, moldador e até reducionista, dos procedimentos avaliativos, quer de instituições, quer de cursos, quer ainda de estudantes. Ademais, são procedimentos que não se pautam em bases pedagógicas, mas antes em teorias administrativas cujo suporte metódico é integrado por recorrência e similaridade de pertinentes práticas e, por isto, disfuncional a mudanças de menos duvidoso sentido qualitativo e, a rigor, de precisão científica. Então, para prevenir riscos de sucumbir a tal ameaça e, coincidentemente, favorecer mudança, há urgente necessidade de contra-avaliar a atual política educacional (declarada) pública.

$\mathrm{Na}$ tentativa de atender essa necessidade, cabe formular ao menos hipótese de trabalho, a qual emerge desdobrada em três aspectos básicos: (a) é admissível que, entre si, coincidam alcance crítico da qualidade educacional a ser promovida pela IES e responsabilidade social dos egressos, desde que tal promoção se entenda interiorizada nos alcances tanto sociogeográfico quanto individual-subjetivo do educando; (b) até a mera abertura à busca de qualidade educacional assim crítica necessita de argumentação ainda inaudita, pois, de outra forma, pesquisadores hão de estatelar-se contra 
um intervencionismo que tem sido radicalmente alheado à dissonância entre "status" (dos teores do marco legal-regulamentar em que se escuda) e ímpeto reducionista (das práticas administrativas, mediante as quais insiste em se afirmar); e (c) procedimentos autoavaliativos, coerentes com um discurso ainda não usual de argumentação, carecem de projetos tecno-cientificamente validáveis, além de libertos em relação à compulsoriedade, vale dizer, sem desta serem vítimas e tampouco cúmplices.

Antes de tudo o mais, cumpre deixar claro que procedência, veracidade e validade, referentes ao que deverá corroborar os teores da hipótese em apreço, reportam-se a objetos aos quais se chega por procedimentos "interdisciplinares", cujo suporte metódico medeie por entre inequivocação quanto produzir intelectualmente (tirante a um avanço na "maiêutica” socrática) e regras cientificizantes do método.

Já a justificativa de um tal suporte metódico reside na situação da fonte do olhar que possibilita percepção e, graças a esta, discernimento pessoal entre apropriar e produzir, desde educação e conhecimentos, passando por meios de vida, até condições de sustentação também coletiva. Todavia, tal discernimento se circunscreve a estrita mediação e jamais substitui pertinência e cientificidade de outros conhecimentos disponíveis. 


\section{B. Concepção de qualidade, heteronomica- mente exposta a disputas ideológicas}

\section{Imprecisões da qualidade sob disputa}

$\mathrm{Na}$ vigente Constituição Federal, a questão da qualidade de ensino emerge correlata a qualificação para o trabalho, a par de promover o "pleno desenvolvimento da pessoa", em pé de igualdade com o também pessoal "preparo para o exercício da cidadania" (Art. 205). Assim, e em termos propriamente legitimados, a qualidade de ensino implicaria considerar a pessoa do educando. Mas, e apesar desta implicação, contará com um princípio de padrão assegurável (Art. 206, Inciso VII $)^{2}$. Ademais, será passível de implementação pela iniciativa privada (Art. 209, Caput), conquanto não sejam dispensadas autorização e avaliação por parte do Poder Público (Inciso II). Assim, e ainda que de forma implícita, precisará de melhoria a ser avaliada no âmbito de um plurianual plano nacional de educação (Art. 214, Inciso III).

Enquanto a Lei Maior se refere a ensino de todos os níveis, a LDB assume "educação escolar, que se desenvolve, predominantemente, por meio de ensino em instituições próprias" e que deverá vincular-se ao "mundo do trabalho" e à "prática social" (Art. $1^{\circ}$, IS $1^{\circ}$ e $2^{\circ}$ ). Nesta perspectiva, a LDB acaba por não mais do que subsumir desenvolvimento da pessoa, ao interpretar qualidade, determinada pela Lei Maior, como

2 Peculiarmente por se tratar de um princípio de seguimento compulsório ao se ministrar ensino, "garantia de padrão de qualidade" é determinação incompatível com o (jamais padronizável) caráter singular-pessoal da qualidade a ser efetivamente implementada. Assim, ultrapassagem dessa incompatibilidade postularia expressões diversas daquela de "qualidade garantida por padrões de condições de oferta" e que prevaleceu no texto da LDB (Inciso IX, Art. $4^{\circ}$, Lei $n^{\circ}$ 9.394, de 20.12.1996). 
ensino mediado por "educação, dever da família e do Estado, inspirada nos princípios de liberdade e nos ideais de solidariedade humana" (Art. $2^{\circ}$ ). A par disso, ensaia realimentar o entendimento de que qualidade seja assunto em cujo teor precisem coincidir institucionalidade e sustentabilidade, além de manter imprecisão sobre qualidade na interação entre pessoa e trabalho, ao repetir a expressão: “(...) insumos indispensáveis ao desenvolvimento do processo de ensino-aprendizagem" (Art. $4^{\circ}$, Inciso IX. Grifo nosso). Em decorrência, é assegurado "em primeiro lugar o acesso ao ensino obrigatório" (Art. 5 , $\$$ $2^{\circ}$ ), e, paralelamente, imputa-se "crime de responsabilidade" no caso de comprovada negligência da autoridade envolvida $\left(\$ 4^{\circ}\right)$. Por outra parte, resta cabalmente implícito que em tais insumos se enquadrem infraestrutura e demais recursos material-técnicos, bem como, a despeito da pessoalidade das condutas a tanto imprescindíveis, docentes cujos perfis a tanto hão de coadunar-se, quanto mais elevados forem os respectivos títulos ou aprofundadas as correspondentes especialidades de tipo de conhecimento e de método.

Conforme Botomé (1996, p. 27-29) a formação de docente de nível universitário presume, além de ser professor, outras quatro profissões - técnico e especialista; pesquisador ou cientista; administrador; e, escritor. Para tanto, a preparação tem sido desigual, além de que a pós-graduação "stricto sensu" tende a intensificar a especialização técnica em um só assunto e no recurso a "algumas (quando não uma única!) técnicas de pesquisa”. Assim, esse profissional há de encarar certos desafios.

[...] desenvolve uma "experiência" que, com frequência muito grande, não o leva a completar as lacunas em sua formação, mas a desenvolver e fortalecer o que é "aceito", o que "funciona" ou 
o que lhe dá "poder", "capacidade de influência", etc. no meio social e institucional. Com isso, consolida-se, progressivamente, um poder cada vez maior (...) que o leva a agir sobre os demais e sobre a instituição de maneira a consolidar não o que vale a pena a longo prazo, para a instituição e para a sociedade, mas o que o leva a "ganhar", "sentir-se seguro", "obter mais poder", "ser aceito e reconhecido", etc. (BOTOMÉ, 1996, p. 27).

A propósito desse risco no processar-se da profissão de professor universitário, cumpre autopoliciamento no sentido de prevenir dissonância de concepções sobre qualidade educacional, inclusive entre avaliadores institucionais, externos e/ou internos.

Apesar do entendimento da LDB sobre educação, bem como da determinação constitucional (Art. 209) a propósito da presença e da sustentação de instituições privadas nas atividades de ensino, há lacunas no pertinente marco regulamentar. As atividades das IES privadas acabam inseridas no mero varejo da regulamentação cabível, assim como à obrigatoriedade de processos burocráticos desfocados quanto à devida pertinência à questão real e socialmente relevante, vale dizer, quanto à referida qualidade educacional na interação entre pessoa e trabalho. Neste sentido, cumpre ressaltar que pesquisa e extensão das IES filantrópicas de direito civil estão constitucionalmente legitimadas a receber recursos do Poder Público (Art. 213, $\ 2^{\circ}$ ). Entretanto, e a princípio, a avaliação institucional externa está legitimada a prejudicar tais IES, à conta de alegadas insuficiências de extensão e, peculiarmente, da circunstância de as cabíveis atividades 
avaliativas incidirem em custos que precisam recair sobre as mensalidades, a ponto de isto significar exclusão à margem de candidatos a estudantes. Ademais, e por força das mencionadas lacunas, proliferam entendimentos imprecisos sobre qualidade e tende a ser enfraquecida sua pertinência ao fenômeno propriamente educacional, a exemplo dos seguintes: (qualidade) de ambiente de trabalho (Parecer CES, no 908/98); (qualidade) determinada por fatores diversos e abrangidos por procedimentos e critérios avaliativos (Lei 9.131/95, Art. 3º); e, (qualidade) de pessoas jurídicas de direito civil, sem fins lucrativos (Decreto no 3.100/99).

Peculiarmente, cabe maior atenção ao entendimento de qualidade educacional no âmbito do macrossistema MECInep, âmbito em que dois ciclos precisam vir diferenciados: (a) ao longo da deflagração da avaliação das IES no sistema federal de ensino superior (na elaboração, tramitação e divulgação da Lei $\mathrm{N}^{\circ}$ 10.861, de 14.04.04, bem como da Portaria $\mathrm{N}^{\circ}$ 2.051, de 09.07.04); e (b) após o teste de campo da obrigatoriedade da autoavaliação institucional das IES particulares (elaboração e divulgação do texto sobre Diretrizes e Instrumento da Avaliação Externa de Instituições de Educação Superior, bem como do Decreto $N^{\circ}$ 5.773, de 09.05.06).

$\mathrm{Na}$ deflagração em causa, houve de emergir entendimento sobre qualidade das autoavaliações, se nestas houver participação dos seus sujeitos - corpos docente, discente e técnico-adminitrativo (MEC/Conaes: s/d, p. 5). Vem a ser qualidade que é passível de patamares e estes devem refletir transformações e mudanças (p. 7). Também significa compromisso com a melhoria da própria qualidade das atividades de cada uma e do conjunto das instituições educacionais ( $\mathrm{p}$. 8). Aparece ainda uma "qualidade do sistema de educação superior" (p. 9). A seguir, como instrumento de política 
educacional, surgem outros entendimentos sobre qualidade, nos quais esta aparece não apenas passível de melhoria e pertinente às atividades de formação de futuros egressos, como também de produção de conhecimentos e de extensão no estrito âmbito de cada IES (p. 9). Há, ainda, qualidade de um bem público, a própria educação, se esta for promovida em acordo com princípios (p. 13), ou que seja "compatível com modalidades de ensino, pesquisa e extensão (p. 17)3. Por fim, cabe destacar uma qualidade institucional que não pode provir de fora e na condição de modelo externo e abstrato, mas precisa ser, em cada IES, "modelo institucional nos termos de sua missão e, a partir dele, deve ser avaliada a instituição real” (p. 18).

Após o teste de campo da obrigatoriedade da autoavaliação das IES, especialmente (e tacitamente) das particulares, o entendimento sobre qualidade tende a desandar em construto, a atingir patamares sempre mais altos e pertinentes à educação superior brasileira em seu conjunto (MEC/Conaes/Inep,

3 Dentre os 7 (sete) princípios arrolados, os 2 (dois) primeiros são preocupantes: $\left(1^{\circ}\right)$ "A responsabilidade social com a qualidade da educação", o qual intriga por ter sido eleito sem ouvir os sujeitos ou agentes, ou seja, a despeito da recorrência e da predizibilidade de conflitos entre autoridade administrativa (MEC/Conaes/Inep) e autoridade de especialista, esta última sendo peculiar a instituições universitárias, ou mesmo, de estrita pesquisa, assim como de tensões organizacionais entre informalidade e formalidade, entre clientes e organização, ou ainda, entre profissionalidade e disciplina burocrática, paralelamente àquela peculiar tensão entre necessidade de iniciativa individual, como imprescindível fonte de criatividade, e planejamento centralizado enquanto veiculador de se recorrer a meios tecnológicos cujo avanço, ao se converter em um fim em si mesmo, inibe criatividade" (MUNIZ; FARIA, 2001, p. 73-74); e $\left(2^{\circ}\right)$ "O reconhecimento da diversidade do sistema", o qual também intriga por dar margem a pretexto de as instituições educacionais públicas acabarem por omitir-se quanto à qualidade educacional inerente à interação entre pessoa e trabalho (alheamento ao problema de a falta de solução ser tida como a própria solução, dada uma conveniente inciência quanto a tributos, e não apenas retornos privados, precipitarem insustentabilidade coletiva). 
2005, p. 4), assim como a ser cultural, verificável (mediante avaliação externa) e atribuível à instituição e à formação dos estudantes (p. 7). Também passa a ser pertinente a processos a serem realizados, assim como à atuação acadêmica e social, além de ser objeto de compromisso e atributo de informações e do sistema como um todo (p. 8). É objeto de destaque, por ser de per si condizente com instituições de educação, sendo, neste aspecto, passível de promoção e referente a processos educativos e científicos (os quais incidem "em uma prática social que afeta e modifica as pessoas, assume perspectiva histórica, plena de sentidos e valores"), assim como atributo, ou conjunto de atributos, do cumprimento da missão de forma a satisfazer expectativas internas dos sujeitos da comunidade acadêmica e externas da sociedade, com padrões aceitáveis de desempenho (p. 8). Resulta referenciada por "estatuto de responsabilidade democrática”, devido a ser promovida pela combinação de critérios científicos e de participação dos atores acadêmicos e sociais (p. 8). Detém valor, definível por parâmetros e, por isso, tende a reinterpretar pertinentes padrões. Estes devem ampliar, ilimitadamente inclusive, o seu significado legal de "insumos" por educando, atendendo tanto a objetivos que, por sua vez, direcionam o processo educativo, quanto a projeto pedagógico e científico da IES (p. 9). Apresenta-se sob referentes que emergem em alcance tanto universal quanto particular. No primeiro caso, tais referentes são compreendidos por “(...) a adequação e a pertinência dos processos de formação, o rigor acadêmico e científico, a condição social, científica e cultural da produção acadêmica, a construção da cidadania e o exercício da democracia" (p. 9). No segundo caso, esses mesmos referentes são específicos (ou) particulares, desde que "vinculados à missão de um conjunto de instituições ou de uma só instituição, que reafirmam as suas peculiaridades e caracterizam seus propósitos 
autoinstituídos" (teor da missão própria e coerência, com este teor, do projeto pedagógico institucional, bem assim com "contextos, atores, processos e atividades, dando atenção às especificidades e, ao mesmo tempo, permitindo o delineamento de uma visão global da instituição" (p. 9). Ademais, (e enquanto institucional) tem "indicadores, em distintos níveis e enfoques", os quais são passíveis de construção e consolidação por diretrizes para a avaliação externa das IES (p. 10). Já enquanto assim passíveis, dependem de exercício permanente de autorreflexão à base de referentes universais e particulares (p. 11). Além disso, e na condição de atributo de informações, incidem em bases (qualitativas) da avaliação externa, bases que "são estruturadas a partir da análise do referencial quantitativo (também de informações) e da comparação, em diferentes níveis de observação, entre o que a IES se propõe a cumprir e a sua capacidade para tal" (p. 12) ${ }^{4}$.

Enfim, e após tantos entendimentos sobre qualidade, em nada surpreende que esta acabe definida de forma circular (o definido, ocorrendo no que o define), inclusive em assertivas de decisiva relevância para a operacionalidade do processo de avaliação externa.

4 A comparação aponta para um desajuste entre situação projetada e situação atingida de atividades acadêmicas, cuja qualidade, diversamente do admitido, há que provir dos respectivos valores intrínsecos ou dos motivos pelos quais, para tanto, acabaram eleitas. Não há máxima aproximação entre as duas situações, questão que se traduz também como riscos interpretativos dos seguintes dizeres (sic): "As bases qualitativas são estruturadas a partir da análise do referencial quantitativo e da comparação, em diferentes níveis de observação, entre o que a IES se propõe a cumprir e a sua capacidade para tal" (p. 12. Grifo nosso). As qualidades objetivas (determinações matemáticas e fórmulas inerentes), segundo Abbagnano (2007, p. 958. Grifo nosso), “... delineariam a natureza de um objeto transcendente à percepção sensível, ao qual esta acenaria como a algo distante”. Em suma, resta cômico, se não fosse trágico, fazer escarcéu midiático, seguido de ameaças de sanções institucionais, à conta de notas arbitrariamente atribuídas a uma IES. 
A dimensão qualitativa tem o objetivo de captar os movimentos institucionais na direção das referências de qualidade estabelecidas nas dez dimensões ${ }^{5}$ do sistema Nacional de Avaliação. A avaliação qualitativa desenvolve-se a partir de indicadores que objetivam compreender e analisar a qualidade dos processos e práticas vivenciados, em uma perspectiva dinâmica e auto-referenciada ( $\mathrm{p}$. 12. Grifos nossos).

A ocorrência do definido na definição desvela a circunstância de que os teores desse excerto de texto destinam-se a avaliadores externos, cuja iniciação lhes favorece entender os próprios entendimentos. Entretanto, avaliadores não assim iniciados têm de admitir que imprecisões conceituais estão a permear situação interna e superposição externa de avaliações, urgindo dar conta da circularidade desses teores.

Após tantas apreciações de entendimentos sobre qualidade, cuja melhoria vem a ser o objetivo justificador das avaliações, internas e externas, há três tendências a levantar: (a) intensifica-se imprecisão sobre significado de qualidade, inclusive enquanto mero atributo de atividades acadêmicas, sem que se desconfie da influência do metropolismo nos contrafortes

5 As dez dimensões são as seguintes: (1 ${ }^{a}$.) a missão e o plano de desenvolvimento institucional; $\left(2^{\mathrm{a}}\right.$.) perspectiva científica e pedagógica formadora: políticas, normas e estímulos para o ensino, a pesquisa e a extensão; $\left(3^{a}\right.$.) responsabilidade social da IES (nas perspectivas da inclusão social, do desenvolvimento econômico e social, meio-ambiente e preservação da memória e do patrimônio cultural); $\left(4^{\mathrm{a}}\right.$.) comunicação com a sociedade; (5 ${ }^{\mathrm{a}}$.) políticas de pessoal, carreira, aperfeiçoamento e condições de trabalho; $\left(6^{a}\right.$.) organização e gestão da instituição; $\left(7^{\mathrm{a}}\right.$.) infraestrutura física e recursos de apoio; $\left(8^{\mathrm{a}}\right.$.) planejamento e avaliação; $\left(9^{\mathrm{a}}\right.$.) políticas de atendimento aos estudantes; e, $\left(10^{\mathrm{a}}\right.$.) sustentabilidade financeira. 
dos discursos oficial e oficioso; (b) a concepção de qualidade enquanto algo inerente à interação entre pessoa e trabalho, apesar de seu "status" constitucional, acaba em sempre menos oportunidades de vir a ser considerada, concomitantemente com a (inconfessa) pretensão de os procedimentos metódicos sobre-estarem ao sujeito, e até mesmo ao objeto, e perfazerem inescapável condição para as ciências se autoafirmarem como domínio único da produção do (auto)-conhecimento de instituição educacional, preterindo-se ética e arte-estética na totalidade educacional; e (c) procedimentos avaliativos passam a ter muito em comum, peculiarmente, práticas administrativas de planejamento estratégico (análise de ambiências para constatação de oportunidades, ameaças, pontos fortes e fracos, a par do apontamento de objetivos, da fixação de metas, da eleição e execução de ações, do acompanhamento e do controle), circunstância que favorece reciprocidade de contágio (e de isenção) quanto à própria falta de qualidade.

\section{Procedimentos autoavaliativos: do alcance estratégico ao caráter "crítico-teoricamente" autoafirmativo}

Para a (inicialmente referida) argumentação ser deflagrada, procura-se demonstrar, neste tópico de texto, que o macrossistema MEC-Inep expõe-se a riscos demasiadamente amplos de assumir imprecisão de componentes de suporte metódico, à medida que os procedimentos avaliativos do ensino superior ocorrem compreendidos em práticas administrativas de planejamento estratégico, práticas que estão a se defrontar com questionamento quanto à sua fundamentação, científica inclusive. 
À primeira vista, tal ocorrência seria justificável, uma vez que, por ora, estaria em pauta apenas a delimitação de um problema de fundo e ainda não mais do que vislumbrado, para não dizer, vitimado a preconceitos: aquele de uma (pré-conceituada e) contínua perda de qualidade por parte do ensino superior que vem sendo promovido, especialmente, pelo segmento privado do correspondente sistema federal. Todavia, até mesmo essa eventual delimitação do problema depara-se com dissonância entre estratégia de política pública sobre qualidade educacional e procedimentos avaliativos desta mesma qualidade.

Estratégia de política pública não tem sido caracterizada por abrangência universalista em sociedades originárias e herdeiras das práticas colonialistas, uma vez que universalismo não veio merecendo atenção nem mesmo nas próprias metrópoles - no caso, Lisboa ou o patrimonialismo junto às cortes portuguesas e, após a independência política, junto a certa elite cuja ampliada reprodução tem tudo a ver com a universidade (que se vem declarando) pública e inclusive filantrópica. Assim, e em tais sociedades, sequer a possibilidade de universalismo, a respeito do que é público, chegou a merecer atenção à altura da pertinente densidade e aprofundamento conceitual. Eis porque, no Brasil, as políticas públicas têm acontecido em relação a públicos-meta (-alvo ou -foco). É que a (presumida) impossibilidade de aquelas políticas serem universalizáveis tem feito com que haja incursão em dualismo legal-regulamentar a respeito de inclusão e exclusão - ambas quanto a acesso à condição de meta, alvo ou foco. Já esse dualismo tem muito a ver com a arraigada assimetria entre resignação e "arrogância reivindicalista" junto às populações nas quais subsiste enraizado. Trata-se de assimetria cuja reprodução muito tem a ver com o "status" legal-regulamentar de intérpretes do alcance público das políticas, a partir da sua (silenciada) situação de incluídos. 
Por implícito que o esteja, dualismo legal-regulamentar também tem sido influente na interpretação do alcance público da política educacional. Trata-se de interpretação cuja fonte não se apercebe de que o seu olhar parte da situação do próprio "status" de sobrepor-se, desde à resignação a insuficiências até à "arrogância reivindicalista" de suficiências, em todos os níveis do processo educativo (infantil, fundamental, médio, superior, pós-graduação). Assim, o alcance do que se admite como público, anteposto a meta, alvo ou foco, costuma vir traduzido como o próprio sobrepor-se, porque este se universaliza na condição de teor político-hegemônico, metódico-epistemológico e material-econômico. Por sua vez, este teor tem estado a cavaleiro de uma vontade que, ao imiscuir-se com desejo (pessoal e/ou corporativamente) incontido, incide em equívocos quanto a seu sentido de coletiva, pública ou universalizada. E, no bojo de tal imiscuição, não há como o atributo (dito) público de uma política apresentar-se com significado construtivo de qualidade, nem mesmo se esta atendesse a (compulsória ou legal-regulamentar) "perspectiva científica e pedagógica formadora" da mais significativa das 10 (dez) dimensões institucionais a serem avaliadas. Ademais, só após o teste de campo dos procedimentos autoavaliativos, tal perspectiva veio a ser menos imprecisamente definida. Isto ocorreu a partir do entendimento que veio a ter a dimensão em causa (a segunda, dentre as inicialmente eleitas, referente a "políticas, normas e estímulos para ensino, pesquisa e extensão") no marco regulamentar das diretrizes para avaliação externa das instituições educacionais (MEC/Conaes/Inep: 2005, 21) ${ }^{6}$.

6 Apesar da explicitação dos conteúdos ter ficado menos imprecisa, resta ainda a implicitude de que "a perspectiva ... pedagógica formadora" não seja científica e, então, ficaria irreconhecível seu significado contributivo para a qualidade. Todavia, com certa boa vontade, há como assumir que pedagógico-formadora seja pertinente ao alcance científico da perspectiva. 
Tal entendimento passou a ser compulsório, além de a relevância da dimensão em foco se tornar mais expressiva (de $10 \%$ para $30 \%$ do total), no sentido de contribuir para a apontada melhoria da qualidade do ensino superior. Esta passagem entrou em dissonância com a (também legal) relevância igualitária dessa mesma dimensão no contexto das 9 (nove) outras, porém, após acabar entendida à base de conteúdos significativamente diversos (sic): "a política para o ensino, a pesquisa, a pós-graduação, a extensão e as respectivas formas de operacionalização, incluídos os procedimentos para estímulo à produção acadêmica, as bolsas de pesquisa, de monitoria e demais modalidades" (item II, art. 3º Lei No 10.861, de 14.04.04).

A própria instituição do Sinaes fora deflagrada como especialidade de política pública em franca dissonância com o alcance universalizado da avaliação a ser promovida. Trata-se de dissonância, em que transparece certa discriminação entre as próprias finalidades do correspondente sistema, conforme os termos do seguinte excerto da pertinente regulamentação.

O SINAES tem por finalidades a melhoria da qualidade da educação superior, a orientação da expansão da sua oferta, o aumento permanente da sua eficácia institucional e efetividade acadêmica e social e, especialmente, a promoção do aprofundamento dos compromissos e responsabilidades sociais das instituições de educação superior, por meio da valorização de sua missão pública, da promoção dos valores democráticos, do respeito à diferença e à diversidade, da afirmação 
da autonomia e da identidade institucional. (Art. $1^{\circ}$, Lei $\mathrm{N}^{\circ}$ 10.861, de 14.04.04. Grifo nosso $)$.

Antes que se ouse interpretar qualidade presente nesse excerto de lei, cumpre alertar que o significado da (pleonástica) expressão "melhoria da qualidade" pretende escudar-se em práticas (bases empíricas) e advirá de uma agregação (traduzida quantitativamente, mediante pesos) de notas (de 1 a 5), exaradas a meio-termo entre objetividade e subjetividade pelos próprios avaliadores, além de se referirem a fenômenos heterogêneos e numerosos. Dessa forma, o recurso a tais notas, para fins de política pública, há que satisfazer um escalar, cujos patamares se traduzem em nada mais do que violência aos fundamentos inescapavelmente singular-particulares do que seja qualidade real quanto a desenvolvimento da pessoa, qualidade já anteriormente definida pela Constituição Federal (Art. 205) e imprecisamente assumida na LDB (Art. $1^{\circ}$, Caput e $\ 2^{\circ}$ ). A mesma tradução deverá vir admitida a propósito de outras expressões, nas quais são insinuadas as categorias correspondentes a eficácia, efetividade, missão e orientação. Por outra parte, não cabe sequer traduzir em conceitos os fundamentos reais correspondentes aos termos: compromissos, responsabilidades, valores, diferença, diversidade, autonomia e identidade, os quais presumem desenvolvimento pessoal, vale dizer, conduta que o desvele.

7 A razão do grifo em "especialmente" reside em certa incoerência entre discurso legal-regulamentar e prática avaliativa, pois a responsabilidade social das IES vem a ser a dimensão 3 dentre as 10 (dez) a serem avaliadas e que, nas diretrizes mais recentemente publicadas, passou a ter peso não compatível com a ênfase assim grifada - apenas $10 \%$, contra $30 \%$ da 2 e $20 \%$ da 5 . (Ver: MEC/Conaes/ Inep. Op. cit. p 21). 
Por preliminares que o sejam, essas considerações servem para argumentar na perspectiva de que a Conaes optou por fazer análises intra- e interorganizacionais com propósitos estratégicos de planejamento, abdicando de recorrer a suporte metódico de pesquisa qualitativa que partisse de um problema suficientemente caracterizado e que lhe possibilitasse solução como objeto denso e aprofundado de conhecimento novo e já imprescindível à causa da educação criticamente universitária. Todavia, com boa vontade e com apelos ideológicos de largo alcance, concede-se que as análises levarão ao fulcro do (presumido ou, talvez, ainda insuficientemente caracterizado) problema federal-sistêmico do ensino superior: meras apostas na (assim dita) contínua melhoria da qualidade, apesar de este ensino ser promovido de forma a buscar ou presumir mais-valia na acepção de "O Capital" (MARX, 1984, p. 246), forma que também prevalece na orientação para a expansão da sua oferta, no desejado aumento da sua eficácia institucional e efetividade acadêmica e social e, especialmente, na ausência de autopoliciamento contra a superficialidade de iniciativas institucionais descompromissadas e socialmente irresponsáveis, as quais, a cavaleiro da missão pública de tal ensino, presumiriam valores democráticos, respeito à diferença e à diversidade, além de afirmação pessoal da autonomia e da identidade - ambas institucionalmente promovidas.

Uma análise, ainda que ligeira, da condição especial que veicula as finalidades do Sinaes, desvela certo ímpeto fragmentário, competitivo e até mesmo ilusionista, o qual é próprio das práticas administrativas, além de restar sob suspeita de contagiar os procedimentos avaliativos a cargo do macrossistema Conaes-Sinaes-Inep. Dentre os modificativos de tal ímpeto, ressalte-se o de ilusionista, tendo-se em conta que irrompem, entre si dissociadas, as expressões que correspondem à melhoria da qualidade educacional e à responsabilidade social 
da IES. Trata-se de dissociação que tem sido notoriamente funcional a preterir qualidade da educação pessoal-desenvolvimentista e a acentuar insustentabilidade coletiva da própria educação universitária, à medida que responsabilidade social só é considerada enquanto iniciativas institucionais cujas oportunidades de se efetivarem incorrem em custos sempre mais elevados, por terem que acontecer fora da ambiência interna da IES e mediante atividades, programas, projetos e setores, os quais tendem a se departamentalizar nesta mesma ambiência. São custos que desandam em elevação das taxas educacionais, ou seja, em exclusão social de candidatos a cursar o ensino superior particular e inclusive público. Tenha-se em conta, ao menos, a possibilidade de tal exclusão, ao se entender responsabilidade social de forma a não buscar, universalizadamente, desenvolvimento pessoal do educando e, por isto, definida segundo os seguintes termos:

[...] significado de sua (IES) atuação, por meio de suas atividades, cursos, programas, projetos e setores, considerando (...) a responsabilidade social da instituição, considerada especialmente no que se refere à sua contribuição em relação à inclusão social, ao desenvolvimento econômico e social, à defesa do meio ambiente, da memória cultural, da produção artística e do patrimônio cultural" (Lei 10.861, de 14.04.04. Art. $3^{\circ}$, Item III. Grifo nosso).

O "especialmente", a propósito desse entendimento da responsabilidade social, é o que motiva certos questionamentos: em ambiência democrática, compulsão (legalidade-regulação) a agir de modo socialmente responsável deixa de incidir em saída utópica? É possível à educação ultrapassar a mera 
ilustração do educando sobre implicações e desdobramentos de suas condutas? Por que sequer tal ilustração é promovida? Até que ponto uma IES precisaria fazer as vezes de organizações diretamente envolvidas com problemas sociais, uma vez que lhe é próprio prevenir estes problemas, em vez de alienadamente vivenciá-los, deixando de incorrer em custos adicionais (e inúteis) da educação que promove? Democraticamente é plausível impor ônus adicional ao custeio da educação, sem consulta e consentimento dos (há tanto) obrigados, ou seja, os próprios estudantes ou seus familiares no caso de IES particular, bem como os contribuintes no caso das públicas? Por que economia, produção e utilidade precisam estar, liminarmente inclusive, excluídas de permear ambiências educativas? Por que respostas a estas e outras questões não serviriam para fazer coincidir qualidade educacional e responsabilidade social? Contrariamente, por que essas mesmas questões e respostas não deixam de ser nulidades, picuinhas e que tais, no discurso legal-regulamentar que torna compulsório, até mesmo, vezo ilusionista de práticas avaliativas?

Com efeito, compromissos e responsabilidades sociais correspondem a condutas e estas necessariamente coincidiriam com ações apoiadas por narrativas de saberes há tanto contextualizadas. Neste sentido, tal coincidência ainda não passa de utopia no ensino superior brasileiro, não por ser nacional, mas por alargamento da própria inadequação a fomentar conduta que é requerida para efetivar avanços científico-tecnológicos, até mesmo aqueles que sejam responsivos às contingências de competir em perspectiva transnacional e, por isso, acabem dissonantes das contextualizadas necessidades pessoais e coletivas. Trata-se de ensino que favorece mera acumulação de narrativas de saberes tidos por conhecimentos, à medida que vezo evolucionista das condutas tem como aprofundar privilégios individuais, corporativos 
e nacionais. De toda forma, nas atuais possibilidades sociogeográficas dos avanços científico-tecnológicos, não caberia a prepostos da educação propriamente universitária serem omissos quanto a enxergar necessidade e eventual suficiência de alteridade de condutas para fazer frente a compromissos e responsabilidades sociais. Alhear-se a essa omissão tem muito a ver com o vezo ilusionista de práticas administrativas, cujo esgotamento de paradigmas teóricos encontra-se em franca aceitação.

Não coincidência entre qualidade da educação e responsabilidade social dos egressos é concomitante com alheamento científico em relação à interface entre forma de sustentar a educação pública e falta de soluções como se fosse a própria solução da sustentabilidade coletiva. Inversamente, essa mesma interface seria aceitável, ao menos como hipótese, no sentido de que qualidade crítica da educação tenha que ser sustentada por contribuições a tanto arrazoadas, em vez de à custa de tributos. A par dessa aceitação e daquela eventualidade, ainda invalidáveis para escudar políticas públicas relacionadas com a educação, no caso a universitária, convém apresentar outro argumento, aquele de que se justifique - apesar da obrigatoriedade de procedimentos avaliativos definidos pelo MEC (Conaes-Sinaes-Inep) e da pertinente imprecisão sobre qualidade educacional-universitária - uma proposta pedagógica a ser ("interdisciplinar" e alterinamente) validada e que tenha como contribuir para que venham a ser, oportunamente fundamentados, os teores da hipótese de trabalho inicialmente levantada. (A próxima subunidade textual volta-se para apresentar os teores desse argumento). 


\section{Alteridade de argumentação quanto à institucionalidade avaliativo-educacional}

No âmbito do macrossistema MEC-Inep, emerge uma determinação de referentes de qualidade inusitadamente sistêmica (de conjuntos) e elementar (IES, curso e estudante), conforme já acima abordada. No caso de uma faculdade isolada, a qualidade sistêmica acaba, a rigor, arbitrada, mediante a integração de níveis avaliativos: institucional (interna e externa), de curso de graduação (autorização, reconhecimento e renovação) e de desempenho dos estudantes (ENADE).

Não há referência sobre interfaces entre aquela determinação e essa integração, mas resta, pelo menos implícito, que o ENADE é um exame para análise dos "conhecimentos adquiridos ao longo do seu processo de formação" (MEC, 2005 , p. 10). E, por ser feito com base em prova por (universo de) curso, incide em abrangência e integração por além desta ou daquela instituição, assim como em homogeneização e até reducionismo quanto ao perfil do egresso. Em tais circunstâncias, não emerge descabido que se desconfie de funcionalidade sociológica a ideologias hegemônicas.

Adicionalmente a tal desconfiança, subsiste uma interface sobre a qual persiste um intrigante silêncio. Vem a ser a (tacitamente admitida) inconciliabilidade do perfil em causa, não apenas com interiorização (e/ou subjetivação pessoal desenvolvimentista) da qualidade educacional-universitária, mas também com alcance contextualizado de narrativas de saberes e, sobremaneira, com conduta singular-particular vinculada também a inequívoco produzir. Ao contrário, é perfil que se ajusta, com extremada afinidade, à metropolização (tendência à sincrônico-topocentria) de atribuída qualidade, cujo inconfesso impingimento perfaz a soltura 
dos discursos que povoam textos oficiosos, oficiais e até mesmo legal-regulamentares. Ainda que esteja a resultar tão somente de acumulação mais ou menos ampla de narrativas de saberes, trata-se de "a" qualidade que incide em condição de o acadêmico, não apenas obter notas de patamar mais ou menos elevado, como também competir por sucesso profissional socialmente convalidado.

Assim, e por força de alheamento quanto à (presumida) qualidade do ensino superior servir à conotação metropolista deste mesmo ensino, a avaliação institucional, ela própria tende a acabar tácita e acriticamente indiferenciadora, reducionista e simploriamente englobalizante dos fenômenos inerentes ao processo educativo. O principal sintoma dessa indicação reside no lidar avaliativo-institucional que persiste estranhado quanto a entender "insumos" como "docência capaz de desenvolver plenamente pessoas". Sobremaneira, há que salientar a obrigatoriedade de pós-graduação, peculiarmente a "stricto sensu", à medida que educador não faz a menor diferença em relação a outros profissionais que apropriam meros "inputs" para os transformar em "outputs" sistêmicos. Em decorrência, a relevância avaliativo-institucional da mera titularidade dos pós-graduados acaba em primarismo humano, pois a eventualidade de existir atuação inequivocamente educacional de docentes, esta ficaria meramente subentendida na ponderação atribuída à dimensão avaliativa correspondente a "perspectiva científica e pedagógica formadora: políticas, normas e estímulos para o ensino, a pesquisa e a extensão" (30\% do total dos pesos, apesar de que políticas, normas e estímulos difiram de ciência e pedagogia, restringindo-se, enquanto perspectiva formadora, aos "umbigos" delas mesmas), além de que, a rigor, essa dimensão tenha tido que perfazer notória ambiguidade com aquela de "responsabilidade social da IES" (20\%, apesar de o perfil de egresso não ultrapassar a condição 
de mero reprodutor de narrativas de saberes). Afinal, até educadores teriam que refletir o fato de serem egressos com perfil nada mais do que aprofundadamente especializado, ou seja, apenas na razão direta do aquilatado progresso como pósgraduados (pós-doutores, doutores, mestres e especialistas). Não se avalia referente algum que faça diferença como "pleno desenvolvimento pessoal", nem mesmo quanto a autodesenvolvimento pessoal dos docentes.

Se a (recém-mencionada) inconciliabilidade for associada às (acima já apontadas) imprecisões quanto à qualidade educacional, fica indicado que padronização referenciadora de qualidade tem a ver com acumulação máxima de narrativas de saberes, enquanto (pretensa) perspectiva pedagógico-formadora, e com especialização a se aprofundar na razão direta de avanço na pós-graduação. Assim, aquela acumulação e esta especialização ficam suspeitas de "estarem" a serviço de acentuados privilégios ocupacionais que apenas subsistem em estreita cumplicidade com tergiversação sobre o que seja propriamente trabalho, sobremaneira quanto ao pertinente alcance de improdutivo. Trata-se de "estado" a condizer com mero escalar de patamares conceituais sobre qualidade de ensino superior.

A interpretação, recém-explicitada, constitui desdobramento da postura de um olhar cuja fonte não se abstrai do vazio em que se situa, seja na totalidade educacional, seja por entre as instituições sob processo (auto)-avaliativo. Se assim não se postasse, "estaria” cega em relação a tal vazio e o converteria em suas próprias costas. Encontrar-se-ia alhures, perdida no interior do conjunto aberto das organizações e no exterior das especificidades enquanto componentes intraorganizacionais. 
É a partir da admissibilidade dessa interpretação que os três aspectos (inicialmente aventados) da hipótese de trabalho passam a fazer sentido. Fica, então, elucidada a existência de (ao menos) suspeitas quanto à presença da iniciativa (indiferenciadamente) privada nas atividades educacionais em contraste com generalidade de "nada consta" quanto à pública. É esta suspeita que não vem perfazendo o fulcro do (presumido) problema que a (auto)-avaliação institucional se propõe a dar conta, seguindo práticas administrativo-estratégicas e não recorrendo a suporte metódico de pesquisa qualitativa em coerência com "objeto" também qualitativo de uma educação que se volte para autoafirmação pessoal-desenvolvimentista a se estender a trabalho, produção e sustentação também coletiva.

A propósito da ausência desse "objeto", cumpre admitir que, dentre as concepções sobre assuntos que dizem respeito ao ser humano, certamente que aquela sobre trabalho situa-se entre as mais compreensivas de equívocos, aporias e subterfúgios. Compreende, inclusive, sua própria antítese, de tal forma que, em matéria de sustentação também coletiva, trabalho incide na questão inevitavelmente administrativoinstitucional da falta de soluções como se fosse a própria solução. Entretanto, sentido inequívoco do que seja trabalho, produção e sustentação não tem intrigado, nem mesmo pedagogias críticas a constarem de diretrizes curriculares.

Adentra-se, neste preciso ponto das argumentações levantadas, ao propriamente inaudito da qualidade de pertinência inequivocamente educativa. Evoca-se, para tanto, a eventualidade de se chegar à coincidência entre, de uma parte, alcance inequivocamente universal de referente de qualidade de uma educação universitária a ser avaliada e, de outra parte, conhecimento do alunado plausível de exame, desde que, previamente a este, o modo inequívoco de produzir encontre 
condições de ser objeto de ensino e objetivo de aprendizagem, ambos a mediarem os conteúdos curricularmente definidos. E estas condições teriam que resultar de pesquisa institucionalmente promovida e a preceder ensino e aprendizagem, perfazendo alternativa institucional de procedimentos avaliativos de qualidade de uma educação a ser promovida.

Com efeito, há como vislumbrar que insuficiências e/ou tergiversação a respeito de educação universitária e de produção justifiquem institucionalidade de avaliações em pedagogia e em ciências administrativas no âmbito de IES. Assim, caráter crítico de pedagogia e de ciências administrativas tem sido solicitado a dar conta de prevenir problemas cuja geração se deve à coincidência de que docentes e administradores se alienam a respeito de inequivocação quanto a produzir e, desta forma, somam-se as alienações e cada profissional acaba por levar ainda mais do que aquelas que previamente já possuía. Em síntese, há admissibilidade de que inequivocação quanto a produzir venha a ser objeto de ambas essas áreas de conhecimento.

Da perspectiva do educando e do educador, a coincidirem com administrando e administrador, a única obrigação (conduta pessoal) a ser institucionalmente universalizável seria aquela de produzir de modo inequívoco, ou seja, como questão estritamente mediadora por entre objetos de ensino e objetivos de aprendizagem. Todavia, não há como essa obrigação ser legal-regulamentar (compulsória), porque incidiria em supressão da liberdade humana que é o fundamento real da cidadania e do direito de ir e vir sem ter que incessantemente dar explicações.

Educação universitária de inequívoca qualidade deve coincidir com aquela voltada para cientificar o educando a respeito de (ainda inauditos) desdobramentos de um seu inequívoco produzir em vez das (sobejamente reconhecidas) 
implicações de não o fazer ou da falta de soluções como se fosse a própria solução da sustentação também coletiva. Já esta falta de soluções não se defrontou com (alteridade de) conduta que a previna e cuja procedência justifique educação de menos duvidoso sentido universitário, ou seja, ensino e aprendizagem do discernimento, a toda prova de veracidade, sobre o significado do que seja produzir.

Então, o mero pensar, correspondente a esse significado, será abertura para autoconhecimento, tendo-se em conta que este somente há de incidir em suficiência de atitudes e condutas, à medida que se estatele contra a (até então irreconhecível) custosidade pessoal de produzir de modo, não só inequívoco (custosidade cujo não arrostamento explique, sem que acabe justificada, a existência de sujeição passiva ou ativa a trabalho), como também e sobremaneira, opcional ou real-dinamicamente liberto. (Trata-se de modo cuja ausência explica a falta de soluções prevalecer como se fosse "a" solução do alcance também coletivo da sustentabilidade). Já a própria custosidade há de reportar-se à "gratuidade" de uma proporção das atividades que são imprescindíveis ao atendimento das necessidades natural-humanas também de estranhos.

Ao se defrontar com essa estranheza, o educando adentrará um dilema existencial-real e ainda inevitável nas vigentes condições institucionais: ou terá que ser, paradoxalmente, vítima e cúmplice de algozes na condição de empregado, padecendo geração de "gratuidade", por além do devido inclusive, ou então, virá a competir pelo privilégio de sobreestar como algoz, capacitando-se a impor tal "gratuidade" a outrem, mediante criação de condições para conduzir-se de forma preponderantemente mercenária ou de mover-se tão somente à conta de certeza e ampliação de recompensas. 
Neste último caso, entretanto, cumpre reconhecer que conduta desnaturada e desumana houve de ser seguida, tendo-se em vista que a dinâmica reprodutiva da espécie, sobremaneira por além do coletivo natural-mínimo, sempre implicou proporção involuntariamente gratuita das atividades, ou dos resultados destas, há tanto necessária e "por parte" dos capazes - nunca "por todos", circunstância pela qual a parte, enquanto e apenas tal, explica-se e é justificada em relação à totalidade. Ao contrário de tal conduta, "Gratuidade" e Razão teriam que estar desimpedidas para reciprocamente se afirmarem, apesar de que, para tanto, as oportunidades têm sido usurpadas, à conta da realização da mais-valia que é indissociável de autoentrega à dinâmica do desejo.

A partir da percepção desse tácito e inescapável dilema, o senso de responsabilidade do educando será evocado e este despertará para o que tem sido supérfluo em objetos de ensino e objetivos de aprendizagem, à medida que, em ambos (objetos e objetivos), ele passará a entrever inconfessa tergiversação sobre produzir e subreptícia justificação para apropriar ou alargar propriedades, enquanto conduta de antemão validada e validável. Ficará, então, aberto ao sentido do que lhe há de significar "crítico-teoria", vale dizer, uma espécie de "substrato-chave" para acesso contextualizado ao (auto)-conhecimento, de forma densa e aprofundada.

Chega-se à interpretação dos fundamentos do dilema acima exposto, graças ao discernimento entre produzir e apropriar. E é este discernimento que deverá perfazer inequívoco e universal referente de qualidade do processo educativo em sua totalidade e, circunstancialmente, também elementar, ao permitir que sejam contextualizados os objetos de ensino e os objetivos de aprendizagem. Paralelamente, surgirão oportunidades para pesquisar questões de qualidade, 
peculiarmente aquela a respeito de uma já imprescindível e desalienante educação de adultos inseridos no mundo do trabalho.

Neste ponto da apresentação do argumento em pauta, um crítico contra-argumentaria que o objeto em consideração já estaria superado. Produzir desanda em nada mais do que apropriar, paralelamente ao que sucederia com educar e avaliar, ou seja, formar e institucionalizar privilégios. Com efeito, e por tácito que o esteja, é o que está a ocorrer pelo agigantamento de certa interface entre formalidade e institucionalidade, a desandar em outra interface entre empregabilidade não universalizável e tecno-cientificidade educacional. Todavia, tais interfaces se agigantam tirante a "salto no escuro" (alcance também coletivo da sustentabilidade encontra-se sempre mais prejudicado, o que transparece nas desigualdades políticas, nas disparidades econômicas e nos desníveis de acesso à tecno-ciência, em perspectiva pessoal, regional ou mesmo continental). Este salto traduz tendência que se acentua apenas, há muito pouco tempo, para que suas múltiplas implicações acabem interpretadas à altura do desafio que representam. Nesta perspectiva histórica, cabe ressaltar o que ainda subsiste de real-concretamente fundamental.

Educar, a princípio, não é avaliar. E, de fato, educar faz sentido e perfaz sua própria razão de ser. Nas mesmas condições, educador não é avaliador institucional, porém faz sentido, assim como incide na sua própria razão de ser, ele dedicar o máximo possível de suas energias, talento, tempo e meios, para dar conta de nada mais do que educar. Tudo o que lhe for impingido, dizendo respeito sempre menos direto com inequívoco educar, fica-lhe gradativamente disfuncional, inútil, prejudicial inclusive. Urge, então, arguir que avaliar melhoria de qualidade de uma educação, sobremaneira 
em alcance institucional, vem a ser ocupação privilegiada de impingir, a outrem, estado paradoxal de vítima e de cumplicidade em relação a tal impingimento, além de tacitamente denunciar-se na condição de atividade alienada quanto a produzir até educação. Tem havido alienação a respeito de produzir inequivocamente e tal alienação tenderá a ser estrutural, caso o produzir educação, além de inequívoco, não venha a ser opcionalmente assumido.

Efetivamente, e antes de tudo na perspectiva meramente institucional, avaliar não tem coincidido com educar. Sobremaneira, e sem importar de que forma ou modo, não tem (assim) coincidido com produzir educação de modo também coletivamente sustentável. Todavia, tem subsistido uma larga intercessão entre forma institucional de avaliar e procedimentos administrativos de acompanhamento e controle no âmbito da função de planejamento. E, se esta função se tornou estratégica, isto pouco ou nada tem tido a ver com produção inequívoca, mas com insuficiências de uma produção que, além de inequívoca, viesse a ser opcionalmente empreendida.

Significado estratégico tem incidido, para todos os efeitos, na privilegiada ocupação de impingir a outrem padecimento de atividades parcial-forçosamente gratuitas, inclusive como autoadmitida produção do impingidor que dela se beneficie. Administrar não tem sido produzir. Ao contrário, faz-se imprescindível (institucional, em rigor), porque, em última instância e à conta dos resignados de sempre, produção coerente com sustentação também coletiva não tem ocorrido sem que algozes imponham, a outrem, estado paradoxal de vítima e de cumplicidade em relação a tal impingimento. E é em tal perspectiva que educação houve de ocorrer alienada, estranhada ou alheada, quanto a se (auto)-produzir de modo inequívoco e, por ainda referencial-utópico que o seja, de 
modo também opcionalmente assumido. Assim, a educação se torna propensa a até mesmo se suicidar, inclusive porque, à custa das futuras vítimas, acaba funcional a realimentar a formação dos exploradores.

Reforça-se, então, o caráter alterino do argumento, vale dizer, veracidade qualitativa de uma educação significará que esta evolva, avance ou mude no sentido de se identificar com objeto de ensino e objetivo de aprendizagem, ambos coincidentes com discernimento, a toda prova, do que seja produzir. Contrariamente, ou seja, enquanto ensino persistir alienado em relação a tal coincidência, qualidade educacional persistirá imprecisa, para não dizer, ilusionista, ensejando oportunidade para o seu fundamento real-concreto acabar parasitado por burocracias, ainda que disfarçadas por alcance institucional de avaliações.

A alteridade do argumento em apreço reside na interface entre contextualizar entendimento sobre relações entre inequívoco produzir e mudança educacional, esta na perspectiva de se achegar a conhecimentos, graças à mediação de sentido "crítico-teórico" em que o discernimento em causa há de incidir. Já esse sentido da mediação, por decorrer de abertura ao caráter também coletivo de toda particularidade sustentatória, contrapõe-se a perspectivas pedagógicas escudadas em mera acumulação de narrativas de saberes tidas por conhecimentos, sobremaneira se tal acumulação for estimulada e, por isto, fadada a fomentar soltura de reivindicalismo criador de insustentabilidade coletiva. À conta dessa contraposição, há como avaliação até coincidir com educação, desde que ocorra mediada por inequívoca produção de questionamento reconstrutivo de conhecimentos, ou seja, mediante contextualização de narrativas de saberes em alcance interiorizado, pessoal e/ou sociogeograficamente. Eis, em síntese, o sentido inaudito do argumento! 


\section{Cientificidade da pedagogia - síntese de um problema ainda em aberto}

Eventual cientificidade de uma proposta pedagógica também há de constituir resposta à ameaça de insustentabilidade coletiva à qual se expõe uma IES isolada e interiorizada. Todavia, até a mera busca dessa cientificidade assume significado de humildade e ousadia. Humildade, porque depende de inequívoca produção intelectual. Ousadia, porque esta produção possibilita levantar, ao menos hipótese, quanto à própria cientificidade.

Nas universidades, ou mesmo nos centros universitários, assim como fora do respectivo curso, a pedagogia não assume o "status" sequer de didática transversa. Em seu próprio campo de atuação, outros campos se fazem valer, o que chega a insinuar que ela perfaça uma espécie de vazio, de vacuidade ou de mera nominalidade a servir de endereço para numerosas ciências serem ensinadas. $\mathrm{Na}$ atualidade, ciências comunicacionais e psicológicas estão a esvaziá-la até mesmo da condição de teoria das práticas didáticas, das quais sempre se valeu para deter esta condição.

$\mathrm{Na}$ Antiguidade Clássica, sem perder sua referência à ação de um escravo acompanhante de crianças que se reuniam com outras para memorizarem narrativas poéticas, se iniciarem em leitura, escrita e música, além de praticarem exercícios físicos, a pedagogia esteve prestes a se emancipar como ambiente de acesso e discussão de propostas filosóficas. Entretanto, segundo Kosick (2002, p. 215), para um historiador que separe a solução da problemática, o pensamento filosófico desandou "de dramático cenário da verdade" em "cemitério de categorias mortas". 
Segundo uma referenciada e sintética pesquisa de Saviani (2007a, p. 15-17), a cientificidade da pedagogia ainda representa uma incógnita. Mas, esse pesquisador aponta que o caminho de ela acabar se colocando como ciência é aquele de se ter em vista "a constituição de algo como uma segunda natureza" do homem, a par de que urge chegar ao pertinente estatuto epistemológico, sobre cuja base precisa-se "estruturar o curso correspondente".

Diversamente, caberia "crítico-teorizar" que se trate de estruturação não apenas em alcance endógeno ao curso, pois o que constituiria problema há de residir em a pedagogia deixar de ser um mero departamento no âmbito de uma IES, inclusive no caso de uma faculdade isolada. Se a instituição é educacional, o objeto da pedagogia terá de mediar toda a pertinente composição.

A partir das três considerações acima explicitadas, cumpre ter em conta que a trajetória existencial do "homem" (ente filosófico) tem sido aquela de construir o absurdo do seu próprio fenômeno, cabendo propriamente à pedagogia apontar esta trajetória e, com isto, opor alteridade de via humanoemancipatória. O fulcro desta via será "gratuidade", a ser opcionalmente gerada. Já esta geração incidirá em atuações cujo campo ainda carece de denominação que signifique ir e vir por entre horizontes de ultrapassagem de toda sujeitação a outrem, desde aquela do antigo escravo até a atual do professor movido a soldo. Entretanto, tal "gratuidade" não perfaz nem mesmo problema no atual contexto das ciências da educação. Em desfecho, adentra-se a uma problematização no sentido de fazer com que uma necessidade seja, enfim e ao menos, assumida como tal. É o que cumpre efetivar, no capítulo logo a seguir apresentado. 
